\title{
Permanent Functional Reorganization of Retinal Circuits Induced by Early Long-Term Visual Deprivation
}

\author{
Stefano Di Marco, ${ }^{1,2,3}$ Vincent A. Nguyen, ${ }^{2,3}$ Silvia Bisti, ${ }^{1}$ and Dario A. Protti ${ }^{2,3}$ \\ ${ }^{1}$ Department of Science and Biomedical Technology, University of L'Aquila, L'Aquila 67100, Italy, and ${ }^{2}$ Discipline of Physiology and ${ }^{3}$ Bosch Institute, The \\ University of Sydney, New South Wales 2006, Australia
}

\begin{abstract}
Early sensory experience shapes the functional and anatomical connectivity of neuronal networks. Light deprivation alters synaptic transmission and modifies light response properties in the visual system, from retinal circuits to higher visual centers. These effects are more pronounced during a critical period in juvenile life and are mostly reversed by restoring normal light conditions. Here we show that complete light deprivation, from birth to periods beyond the critical period, permanently modifies the receptive field properties of retinal ganglion cells. Visual deprivation reduced both the strength of light responses in ganglion cells and their receptive field size. Light deprivation produced an imbalance in the ratio of inhibitory to excitatory inputs, with a shift toward larger inhibitory conductances. Ganglion cell receptive fields in visually deprived animals showed a spatial mismatch of inhibitory and excitatory inputs and inhibitory inputs were highly scattered over the receptive field. These results indicate that visual experience early in life is critical for the refinement of retinal circuits and for appropriate signaling of the spatiotemporal properties of visual stimuli, thus influencing the response properties of neurons in higher visual centers and their processing of visual information.
\end{abstract}

\section{Introduction}

In mammals, visual experience is critical for the normal development of the neural circuitry of the visual pathways (for review see Grubb and Thompson, 2004; Huberman et al., 2008). Visual deprivation in early development leads to a loss of responsiveness and orientation selectivity in cortical cells, reduced visual acuity and convergent strabismus (Cynader et al., 1976; Mitchell, 1988). These effects are mostly reversible if normal visual experience is allowed before the end of a developmental critical period. Although initial evidence suggested that deprivation affects principally the circuitry of the visual cortex (Wiesel and Hubel, 1963; Baro et al., 1990), recent evidence demonstrates changes at several levels of the visual pathways.

The development and maturation of individual retinal ganglion cells (RGCs) have been described in terms of both their morphology (Maslim and Stone, 1988; Bodnarenko et al., 1999; Diao et al., 2004; Mehta and Sernagor, 2006a,b; Coombs et al., 2007) and functional responsiveness and receptive field (RF) organization (Masland, 1977; Tootle, 1993). Pioneering experiments showed that short-term blockage of input from $\mathrm{ON}$

Received Aug. 7, 2009; accepted Sept. 19, 2009.

This work was supported by Australian National Health and Medical Research Council of Australia Grant 307622 and Australian Research Council Grant DP0988227 to D.A.P., Programmi di ricerca di Rilevante Interesse Nazionale 2006, and From Molecules to Man (Agenzia Spaziale Italiana project) to S.B., and Association for Research between Italy and Australia and Programmi Operativi Regionali (Abruzzo) awards to S.D.M. We thank Drs. Bogdan Dreher, Krishna Ghosh, Cathy Leamey, Atomu Sawatari, Samuel Solomon, and Jonathan Stone for critical input and comments on this manuscript. S.B. and D.A.P. conceived the experiments. S.D.M., V.A.N., S.B., and D.A.P. designed the experiments. S.D.M., V.A.N., and D.A.P. performed the experiments. S.D.M. and D.A.P. analyzed the data. D.A.P. wrote the analysis software, and S.B. and D.A.P. wrote the paper.

Correspondence should be addressed to Dr. Dario A. Protti, Anderson Stuart Building (F13), Discipline of Physiology and Bosch Institute, The University of Sydney, NSW 2006, Australia. E-mail: dariop@physiol.usyd.edu.au. DOI:10.1523/JNEUROSCI.3854-09.2009

Copyright $\odot 2009$ Society for Neuroscience 0270-6474/09/2913691-11\$15.00/0 depolarizing bipolar cells reversibly delays the stratification of RGC dendritic trees (Bodnarenko and Chalupa, 1993; Bodnarenko et al., 1995). Later studies showed that dark rearing prevents and delays the developmental pruning of RGC dendritic trees (Tian and Copenhagen, 2003; Landi et al., 2007; Liu et al., 2007b). Visual experience also determines the proportion of bistratified ON-OFF ganglion cells, and the rate of spontaneous synaptic activity (Tian and Copenhagen, 2001, 2003; Landi et al., 2007; Liu et al., 2007a). Although the mechanisms of these environmental influences on RGC development are unknown, it is likely that activity-driven refinement modulates genetically programmed circuits (Wang et al., 2001; Mumm et al., 2005). Changes in synaptic activity occur in parallel with the segregation of RGC dendrites. Tian et al. (2001) reported a surge in the frequency of spontaneous synaptic events in mice RGCs at postnatal days 22-27 (P22-P27), which is reversibly suppressed by dark rearing (Tian and Copenhagen, 2001). More recently, it was shown that early visual deprivation produces permanent changes in the spontaneous synaptic activity recorded from rat RGCs (Giovannelli et al., 2008).

Early in development, GABA-mediated currents in amacrine cells and RGCs are depolarizing and then, due to a developmental shift in the chloride equilibrium potential, become hyperpolarizing (Zhang et al., 2006). Depolarizing GABAergic activity plays a crucial role in modulating the bursting activity of RGCs (Fischer et al., 1998) and the spatial and temporal properties of retinal waves (Sernagor et al., 2003; Leitch et al., 2005; Wang et al., 2007). It is not known, however, whether the development of retinal circuits involves changes in the strength and/or spatial distribution of light-evoked inhibitory and excitatory inputs onto RGCs.

We have examined RF organization and response strength in RGCs in normal controls and in rats born and raised in complete 
darkness during the critical period and then returned to normal environment. We quantified the contributions of inhibitory and excitatory inputs onto morphologically identified RGCs. The RF structure of RGCs was investigated by mapping the spatial distribution of inhibitory and excitatory inputs. We found that visual deprivation induced permanent functional changes in RGC responsiveness due to an increase in inhibitory input and a spatial mismatch of inhibitory and excitatory inputs. These results show that early visual experience is critical for the refinement of retinal circuits, and suggest that abnormal visual experience during the early postnatal period impacts on the properties of neurons in higher visual centers and consequently on vision and visually guided behaviors.

\section{Materials and Methods}

Preparation of the animals. Long-Evans rats were born and reared in complete darkness for different time periods: 6 rats for $\sim 4$ months (postnatal day 119, P119), 2 rats until P77 and 12 rats until P62. To ensure that animals were completely light deprived, the animal facility for darkrearing had a double door and infrared goggles were used to inspect and feed the animals. Animals were then exposed to normal light/dark cycles $(12 \mathrm{~h} / 12 \mathrm{~h})$ until experiments commenced with this recovery period ranging from 2 to 8 months, therefore we call them dark-reared/recovered, DR/R. Long-Evans rats of matching ages reared in normal light/ dark cycles were used as controls.

Experimental procedures. Animals were dark-adapted for at least $2 \mathrm{~h}$, anesthetized with isofluorane and killed by intraperitoneal injection with pentobarbitone $(120 \mathrm{mg} / \mathrm{kg})$. The dissection procedures were performed in the dark under infrared illumination with only occasional exposure to dim red light. Eyes were enucleated and transferred to a Petri dish containing carboxygenated Ames medium. The cornea, iris, lens, and vitreous were subsequently removed and the retina detached from the sclera. A hemiretina was placed photoreceptor side down in the recording chamber and transferred to the microscope stage, where it was continuously perfused with carboxygenated Ames medium heated to $\sim 35^{\circ} \mathrm{C}$. Cells were viewed on a video monitor coupled to a CCD camera mounted on an Axioskop microscope (Carl Zeiss) illuminated with infrared light. All animal procedures followed the guidelines for animal experiments issued by the University of Sydney and the Australian Code of Practice for the Care and Use of Animals for Scientific Purposes and in agreement with the European Directive 86/609/EEC requirements.

Electrophysiological recordings. Whole-cell recordings were obtained from RGCs in whole-mount retinas in current- and voltage-clamp mode using an EPC10 patch-clamp amplifier (HEKA Elektronik). For currentclamp recordings, patch electrodes were filled with an intracellular solution containing $\mathrm{K}^{+}$as the main cation and gluconate as the main anion (K-Glu: 140, HEPES: 10, EGTA: $10, \mathrm{MgCl}_{2}$ : 4.6, $\mathrm{CaCl}_{2}$ : 1, ATP-Na: 4, GTP-Na: 0.5, in mM). For voltage-clamp recordings $\mathrm{Cs}^{+}$and methanesulphonate were used as the main cation and anion, respectively (in mм: 110 CsMeth, 5 tetrabutylammonium, 20 HEPES, 10 EGTA, $4.6 \mathrm{MgCl}_{2}, 4$ ATP-Na, 0.5 GTP-Na, 20 creatine phosphate, and $250 \mathrm{U} / \mathrm{ml}$ creatine phosphokinase). In voltage-clamp experiments, voltage-gated sodium currents were blocked by adding $5 \mathrm{~mm}$ QX-314 in the intracellular solution. Intracellular solutions contained $2 \%$ Lucifer yellow (LY) for cell identification. Ames medium was perfused at $\sim 3 \mathrm{ml} /$ $\min$. When $\mathrm{Cs}^{+}$or $\mathrm{K}^{+}$intracellular solutions were used, liquid junction potentials of -10 and $-5 \mathrm{mV}$, respectively, were subtracted from voltage values. Patch pipettes of 6-8 $\mathrm{M} \Omega$ were used; series resistance usually ranged between 25 and $35 \mathrm{M} \Omega$ and was left uncompensated. The chloride reversal potential $\left[E_{\mathrm{Cl}}^{-}\right]$for these solutions was calculated to be approximately $-55 \mathrm{mV}$.

Visual stimuli. Achromatic stimuli were displayed via a DLP projector (refresh rate $60 \mathrm{~Hz}$ ) through the microscope optics and focused onto the photoreceptors. Stimuli consisted of spots of different diameters (varying from 30 to $1200 \mu \mathrm{m}$ ) and annuli; ON responses were elicited with bright stimuli on a dark background, whereas OFF responses were evoked with dark stimuli on an illuminated background. Stimuli were generated using EXPO, courtesy of Dr Peter Lennie (University of Rochester, Rochester, NY). Most of the experiments were done with a back- ground luminance of $0.0005 \mathrm{~cd} / \mathrm{m}^{2}$, whereas stimulus intensity was $0.25 \mathrm{~cd} / \mathrm{m}^{2}$.

Analysis. Area response functions were estimated from the spike rate of light responses recorded in current-clamp mode. Spikes were detected using an off-line routine to detect the location of maxima by calculating the smooth first and second derivative of the membrane potential signal and comparing it to a threshold. If the amplitude at that point was above threshold (usually $>0 \mathrm{mV}$ ), it was considered to be a spike. Area response functions were also estimated from the amplitude of light-evoked postsynaptic potentials, in which spikes were removed by linear interpolation of the membrane potential signal $4 \mathrm{~ms}$ before each spike and $\sim 10$ ms after each spike (Demb et al., 1999). Mean amplitude of light-evoked responses was calculated for depolarizing responses (EPSPs), and hyperpolarizing responses (IPSPs) when present, in response to stimuli of preferred contrast. Peak responses (EPSPs or IPSPs) were detected and their amplitude measured as the difference between a baseline averaging $200 \mathrm{~ms}$ before stimulus delivery and the average membrane potential across $40 \mathrm{~ms}$ following peak responses. Thus, these values represent the early phase of the light-evoked response.

To quantify the extent of similarity between RFs of RGCs measured at different stimulation frequencies, a similarity index (SI) was used. This was defined as the Pearson correlation coefficient between vectors derived from the RF maps obtained at the two different frequencies, similar to the analysis for pairs of neurons used by DeAngelis et al. (1999). SI was estimated for both spatial and spatiotemporal RF maps and an SI close to 1 denotes maps that have very similar shapes, whereas -1 represents maps with opposite polarities and intermediate values indicate different degrees of similarity.

We defined the pair-pulse index (PPI) as the ratio of the magnitude of a light-evoked response to a second stimulus to the magnitude of response to a first stimulus. Responses were elicited with the same stimulus size and paired stimuli were spaced in time by intervals between 2.5 and $11 \mathrm{~s}$. Similar PPI values were obtained when either the amplitude or spike count of the light-evoked responses were used.

Conductance analysis. Light-evoked synaptic inputs were analyzed in terms of the magnitude of the excitatory and inhibitory conductances, using similar techniques to those described by Borg-Graham (2001) and Taylor and Vaney (2002) as well as by their ratios. To dissect excitatory $\left(G_{\text {exc }}\right)$ and inhibitory $\left(G_{\text {inh }}\right)$ conductances, the total synaptic conductance $\left(G_{\mathrm{T}}\right)$ and reversal potentials $\left(E_{\text {rev }}\right)$ of light-evoked synaptic currents were first calculated. For this purpose, light-evoked synaptic currents were elicited by displaying spots of different diameters (or annuli) at different holding potentials, from -90 to $+40 \mathrm{mV}$ stepped every $10 \mathrm{mV}$. The mean amplitude of $10 \mathrm{~ms}$ segments of light-evoked synaptic currents with respect to baseline (current amplitude averaged for $200 \mathrm{~ms}$ before stimulus presentation) was used to plot current-voltage plots. From these, reversal potential $\left(E_{\text {rev }}\right)$ and total conductance $\left(G_{\mathrm{T}}\right)$ were estimated from the crossing at current $0 \mathrm{pA}$ and the slope of the linear fit of the $I-V$ relation, respectively. $G_{\text {exc }}$ and $G_{\text {inh }}$ were derived according to the following formulas:

$$
\begin{aligned}
G_{\text {inh }}(t) & =\frac{G_{\mathrm{T}}(t)^{\star}\left(E_{\text {rev }}(t)-E_{\text {exc }}\right)}{E_{\text {inh }}-E_{\text {exc }}} \\
G_{\text {exc }}(t) & =\frac{G_{\mathrm{T}}(t)^{\star}\left(E_{\text {rev }} r(t)-E_{\text {inh }}\right)}{E_{\text {exc }}-E_{\text {inh }}}
\end{aligned}
$$

where $E_{\text {exc }}$, the reversal potential of excitatory currents, was considered to be $0 \mathrm{mV}$, and $E_{\mathrm{inh}}$, the reversal potential of chloride, was estimated to be $-55 \mathrm{mV}$. When $E_{\mathrm{rev}}$ was more positive than $0 \mathrm{mV}, E_{\mathrm{exc}}$ was considered to be just exceeding the most positive value of $E_{\text {rev }}$ and when $E_{\text {rev }}$ was more negative than $-55 \mathrm{mV}, E_{\text {inh }}$ was considered to be just below the most negative value of $E_{\text {rev }}$.

Receptive field mapping. The location of excitatory and inhibitory inputs within the RF of an RGC was investigated by flashing a bright spot on a dark background or a dark spot on a bright background for $400 \mathrm{~ms}$ in a square grid of 49 equidistant locations following a fixed sequence, with the center of the grid aligned with the RGC under recording. Normally, at this position the center produced the maximum excitatory in- 
put but occasionally it had to be realigned to meet this condition. To increase signal-to-noise, spots were displayed twice at each location of the grid. Although presentation in a fixed sequence at high frequency could introduce artifacts in RF maps if frequency-dependent components are involved in generating synaptic responses, as shown to occur for a subset of cells, results from the presentation of the second sequence were highly consistent with the first presentation. Spot sizes of minimum diameter to elicit both direct excitatory and inhibitory input were used and the central stimulus coordinate was selected as the location that elicited the largest excitatory current, which in general coincided with the location of the ganglion cell somata. In most of the cells, we used spot sizes as small as 30 or $50 \mu \mathrm{m}$ and separation between spots was either 30 , 50 or $80 \mu \mathrm{m}$. Recordings were performed at the reversal potential of excitatory and inhibitory currents ( 0 and $-55 \mathrm{mV}$, respectively) with the same stimulus, which allowed us to isolate the light-evoked inhibitory and excitatory input. The magnitude of light-evoked excitatory and inhibitory currents was quantified as the area of the inward and outward currents, respectively, by integrating the signal (i.e., the light-evoked charge transfer).

The location of the largest values of direct excitatory and inhibitory currents (and the second largest value, when it was at least $80 \%$ of the maximum response) was extracted for each cell from the RF maps and plotted as distance from the center.

In addition, we used a measure to quantify and compare the RF maps of excitatory and inhibitory inputs from DR/R and control cells, similar to that used by Akerman et al. (2002) for the quantification of ON and OFF inputs in the dorsal lateral geniculate nucleus (dLGN). This was quantified as the RF scatter, which gives an average measure of the degree of spatial separation of the pixels that generate excitatory and inhibitory inputs above a certain threshold.

RF scatter $=\left\langle\operatorname{dist}\left({ }_{i, j}\right)\right\rangle_{i, j}$ Exc-Inh $>T_{\text {, where } \operatorname{dist}(}\left({ }_{i, j}\right)$ represents the distance between positions $i$ and $j$, and $\left\langle\operatorname{dist}\left({ }_{i, j}\right)\right\rangle_{i, j} \operatorname{Exc}-\operatorname{Inh}>T$ denotes the mean distance between all unique pairs of excitatory positions $i, j$ with respect to all inhibitory positions $i, j$ in which the magnitude of the light evoked response (excitatory or inhibitory) exceeds a threshold $T$, set at $80 \%$ of the maximal response. The number of excitatory and inhibitory subunits that fulfill this criterion was also estimated. RF scatter is maximized when the excitatory and inhibitory subfields are individually scattered across visual space and minimized when they are each localized into single subfields within a small area.

Spatial tuning of excitatory inputs was assessed by quantitative estimation of the center-surround receptive field parameters by fitting the normalized amplitudes of the light-evoked charge transfer (LEC) in response to spots of different diameter in RGCs voltage-clamped at $-55 \mathrm{mV}$ with a difference of Gaussians (DOG) model (Rodieck and Stone, 1965). The DOG model assumes the representation of the receptive field center as a narrow, large amplitude Gaussian and of the surround as a broader, smaller amplitude Gaussian of opposite polarity. The fit provided four parameters, namely the strength and radius of the center and surround Gaussians which were obtained from the equation:

$$
\text { LEC } r=\kappa_{c} \exp \left[-\left(r / r_{c}\right)^{2}\right]-\kappa_{s} \exp \left[-\left(r / r_{s}\right)^{2}\right],
$$

where $\kappa_{\mathrm{c}}$ and $r_{\mathrm{c}}$ represent the strength and radius of the center, and $\kappa_{s}$ and $r_{s}$ represent the strength and radius of the surround. The ratio of the integrated volume of the surround to center was calculated to provide an estimate of the degree of surround suppression in response to large spot stimulation.

Data analysis was performed using custom written routines in Igor Pro (Wavemetrics). Data are presented as mean \pm SE and their statistical significance was evaluated with the Student's $t$ test, except when otherwise indicated.

\section{Results}

\section{Receptive field properties of RGCs in DR/R animals are profoundly altered}

We first investigated whether early visual experience affects the basic RF properties of RGCs. In control animals, RGCs displayed normal area response functions characteristic of cells with classi- cal antagonistic center-surround RF organization (Kuffler, 1953; Enroth-Cugell and Robson, 1984). Figure $1 A$ shows representative recordings from a control RGC, in which the strength of the light-response clearly increases with increasing spot diameter up to a certain size after which the magnitude of the response decreases. The area response function for this RGC, quantified in terms of number of spikes and amplitude of the light-evoked PSP (L-PSPs) augmented with increasing spot diameters up to $\sim 300$ $\mu \mathrm{m}$ and then rolled off in response to larger spot diameters (Fig. $1 C$ ), denoting the inhibitory influence of surround illumination. Overall, RGCs from DR/R animals displayed weaker responses to light stimulation. Maximal responses were recorded with the smallest spot diameters tested $(30-60 \mu \mathrm{m})$ with responses rolling off for larger spot sizes, denoting a strong surround inhibition. A representative example of light responses of an RGC from a DR/R animal raised in complete darkness for the first 4 months of life with a recovery period of $51 / 2$ months in a normal light cycle is shown in Figure $1 B$. The number of impulses and strength of depolarization are largest for the smallest spot size used, whereas exposure to larger spot sizes elicited weaker responses. Furthermore, stimulation with larger spots produced direct hyperpolarizing responses, suggesting a blockade of the excitatory center response and strong direct inhibitory input. The area response function (for both spike count and amplitude of the L-PSPs) for this cell shows that the peak response corresponds to the smallest spot size used and as spot size increased, a clear and strong surround inhibitory effect was observed (Fig. $1 D$ ). In this cell, quantification of the number of spikes versus spot diameter shows that spots larger than $200 \mu \mathrm{m}$ failed to evoke any spikes, whereas quantification of the L-PSPs measured as the early phase (first $\sim 40 \mathrm{~ms}$ ) of the change in membrane potential shows that spots larger than $400 \mu \mathrm{m}$ produced hyperpolarizing or very weak depolarizing responses. Figure $1 E$ (circles) displays the averaged normalized area-response function of the response to preferred stimulus contrast for 14 RGCs (9 ON, 3 OFF and 2 ON-OFF) from control animals showing that the classical RF structure comprises an excitatory center for spots between 100 and $150 \mu \mathrm{m}$ and an inhibitory surround for larger spots reaching $1200 \mu \mathrm{m}$. The average of normalized area response functions of 10 RGCs ( 6 $\mathrm{ON}$ and $4 \mathrm{ON}-\mathrm{OFF}$ ) recorded from $\mathrm{DR} / \mathrm{R}$ animals shows a striking difference in the RF profile (Fig. $1 E$, inverted triangles). Responses of maximal strength were observed when very small spots were used and their magnitude decreased abruptly as spot sizes increased. In addition, the degree of inhibition due to surround illumination was much greater, producing complete inhibition for spots larger than $200 \mu \mathrm{m}$. The difference in the response strength was also observed in the mean amplitude of the L-PSPs elicited with spots of optimal size and measured from responses in which spikes were filtered out. Figure $1 F$ shows that the average peak amplitude of L-PSPs of ON cells and the ON response of ON-OFF cells was significantly smaller $(p<0.01)$ in RGCs from $\mathrm{DR} / \mathrm{R}$ animals ( $16 \pm 1.3 \mathrm{mV}, n=10$ cells) than that of control animals $(24 \pm 2.3 \mathrm{mV}, n=11$ cells $)$. Overall, we found no significant differences in the RF profiles of RGCs from animals with different recovery times (data not shown), although they were significantly different to control animals. For this reason, data from animals with recovery periods from 2 to 8 months were pooled and analyzed together.

\section{A subset of RGCs from DR/R animals displayed atypical spatio-temporal receptive field properties}

The observed difference in RF profiles led us to examine in more detail the responses of some individual cells that seemed to ex- 
hibit even more atypical behavior. We found a subset of RGCs recorded from DR/R animals ( 3 of 7 cells tested) that displayed strong habituation, whereas no cells of 9 cells tested from control animals displayed this type of response; the difference between the two groups is significant ( $p=0.05$, Fisher's exact test). To estimate area-response functions, we typically stimulated with spots at interstimulus interval (ISI) of $5 \mathrm{~s}$. In this particular subgroup of cells, however, stimulation at ISI of $5 \mathrm{~s}$ elicited responses only to the first and occasionally second stimuli, and subsequent stimulation failed to elicit any response (unlike all recordings from control animals as well as from $>40$ RGCs in the retina of normally reared mice, our unpublished observations).

Thus, we investigated the spatial and spatiotemporal structure of their RFs using lower frequency stimulation. Figure $2 A$ illustrates typical area response functions obtained from a control cell at 5 and $20 \mathrm{~s}$ interstimulus intervals. As expected, the strength of the response increased with an increase in spot diameter, peaking at $300 \mu \mathrm{m}$ with larger spots rendering smaller responses, denoting surround inhibition. In control cells, an interesting observation was that the strength of the inhibitory surround was greater at a lower stimulation frequency. Similar changes in spatial tuning profiles at different frequencies were observed in 5 RGCs from control animals. Figure $2 B$ shows a representative area-response function for an RGC from a DR/R animal, showing spike counts recorded at 5 and $20 \mathrm{~s}$ ISI. The area-response function elicited at $5 \mathrm{~s}$ ISI shows maximum spike counts in response to the smallest spot which then decays very rapidly with increasing spot diameters. Area-response functions elicited at ISI of $20 \mathrm{~s}$ displayed a different profile, consisting of a large response to the smallest spot used which then decayed and subsequently increased for spot diameters between 150 and $400 \mu \mathrm{m}$. A similar pattern was observed in 3 cells for both the spike count and L-PSPs amplitude. This frequency dependence suggests that there might be two inhibitory mechanisms operating over different time courses, one activated by stimulation of local networks $(<200 \mu \mathrm{m})$ which is frequency insensitive and another one activated by stimulation of peripheral networks $(>200 \mu \mathrm{m})$, which is frequency sensitive. Local inhibition would presumably be mediated by narrow field amacrine cells, whereas peripheral inhibition would be mediated by wide field amacrine cells.

To quantify the changes of the RF properties in the space-time domain as a function of stimulation frequency, we constructed spatiotemporal RF maps. Figure $2 C$ shows the spatiotemporal RF maps for responses evoked at ISI of 5 and $20 \mathrm{~s}$ for an RGC from a control animal. The spatiotemporal RF maps show a similar profile for both polarity and strength of the responses for both

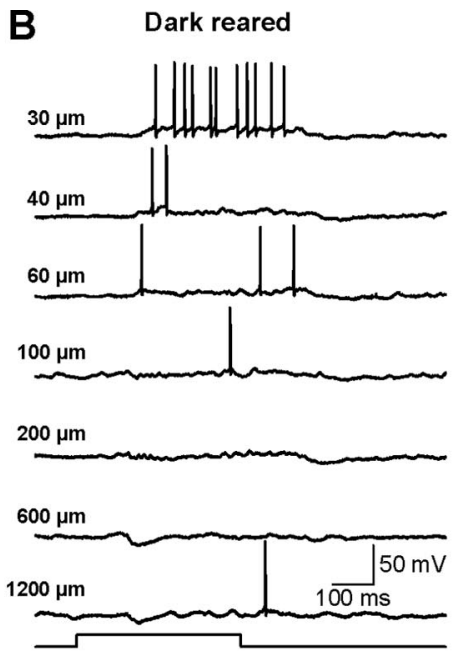

D

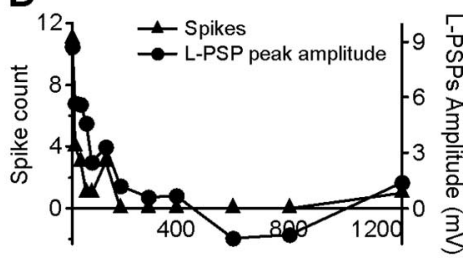

Spot diameter $(\mu \mathrm{m})$

$\mathbf{F}$

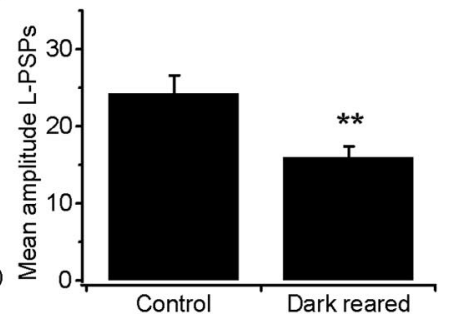

Figure 1. Dark rearing permanently modifies receptive field organization in $\operatorname{RGCS} . \boldsymbol{A}, \boldsymbol{B}$, Representative light-evoked responses of an A response function for the control cell shown in $A$ quantifying the average spike count of 5 repeats, one of whic (he axis), and the average amplitude of 4 repeats of the L-PSPs (right axis) displays the profile of cells with PSP from control and DR/R animals, respectively. $\boldsymbol{F}$, Mean amplitude of L-PSPs evoked by optimal spot size (producing the strongest response) of control cells was significantly larger than that of $D R / R$ animals ( ${ }^{* *} p<0.01$, mean $\pm S E M$ ).

stimulation frequencies; low-frequency stimulation, however, produced stronger and longer-lasting depolarizing as well as hyperpolarizing responses. The spatiotemporal RF maps at ISI of 5 and $20 \mathrm{~s}$ of a cell from a DR/R animal (Fig. 2D) are strikingly different. At high-frequency stimulation, this cell showed an early inhibitory response for all spot sizes with the strongest inhibition for spots smaller than $80 \mu \mathrm{m}$ and an overall lower excitability. The structure of the spatiotemporal RF map at low frequency shows larger response amplitudes for all spot sizes over the time course of the response. The patterns observed for the spatiotemporal RF maps at both frequencies in cells from control and DR/R animals clearly account for the spiking behavior illustrated in Figure 2, $A$ and $B$.

To quantify the degree of difference or similarity between spatial RF maps of the spike response, we estimated the similarity index (SI, see Materials and Methods). Figure $2 \mathrm{E}$ shows the average SI for the spatial profile of RF maps at ISI of 5 and $20 \mathrm{~s}$ for 5 typical control cells and the 3 more atypical cells from DR/R 
A

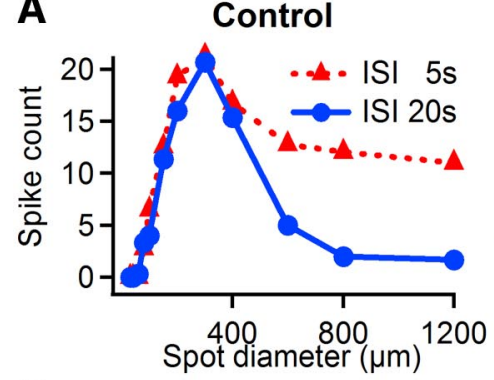

C
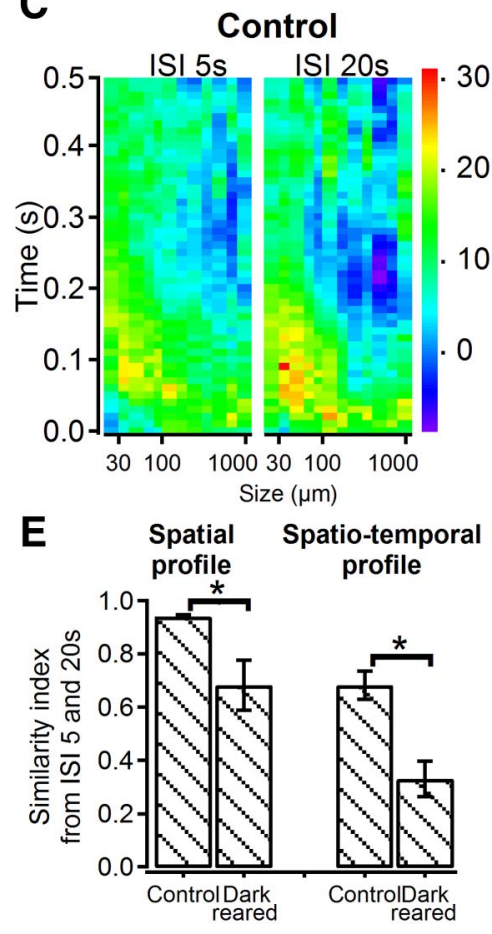

B

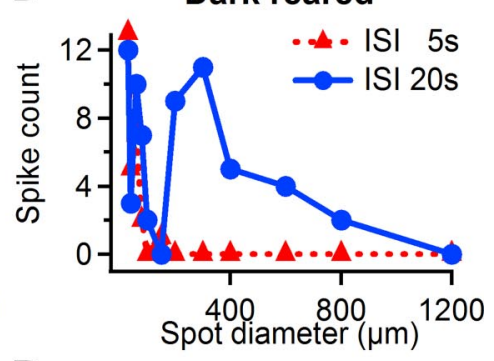

D

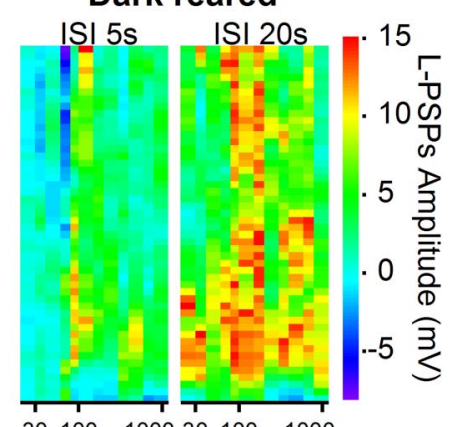

$30100100030100 \quad 1000$ Size $(\mu \mathrm{m})$

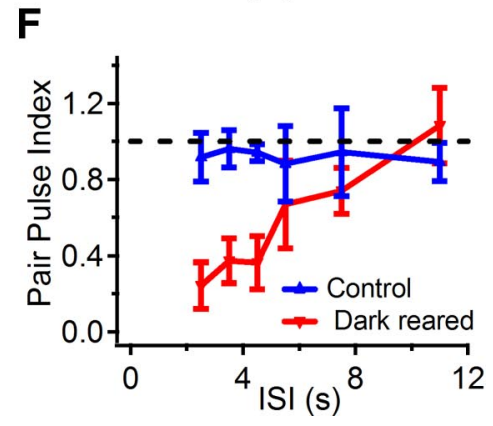

Figure 2. Frequency-dependent changes in RF properties of three cells from $D R / R$ animals with unusually strong inhibition. A, representative area response function of an RGC from a control animal obtained via stimulation at an ISI of 5 and $20 \mathrm{~s}$; the strength of the center response was the same at both frequencies and the strength of the surround was much larger at lowfrequency stimulation. $\boldsymbol{B}$, Representative area response function of one of the three cells from DR/R animals obtained at 5 and $20 \mathrm{~s}$ interval. C, Spatiotemporal RF map of light evoked postsynaptic potentials at an ISI of 5 and 20 s for an RGC from a control animal. Abscissa, spot diameter in log scale, ordinate: time binned every $10 \mathrm{~ms}$. Pseudocolor scale applies to both maps. D, Pseudocolor spatiotemporal profile of L-PSPs for a cell from a DR/R animal at 5 and $20 \mathrm{~s}$ ISI. Abscissa and ordinate are as in C. E, Similarity index of spatial and spatio-temporal profiles at 5 and $20 \mathrm{~s} / \mathrm{SI}$ for $4 \mathrm{RGCS}$ from control animals and $3 \mathrm{RGCS}$ from DR/Ranimals. The SI indices computed for spatial and spatiotemporal of cells from control and DR/R animals elicited at ISI of 5 and 20 s showed significant differences $\left({ }^{*} p<0.01\right)$. $\boldsymbol{F}$, Pair pulse index measured with twin pulse stimulation for 4 and 3 RGCs from control animals and DR/R animals (see Materials and Methods).

Table 1. Percentages of ON, OFF, and ON-OFF cells in control and DR/R animals

\begin{tabular}{lll}
\hline & $\begin{array}{l}\text { Percentage } \\
\text { (number of cells) }\end{array}$ \\
\cline { 2 - 3 } Response type & Control & DR/R \\
\hline ON & $44 \%(34 / 77)$ & $51 \%(23 / 45)$ \\
OFF & $31 \%(24 / 77)$ & $16 \%(7 / 45)$ \\
ON-OFF & $25 \%(19 / 77)$ & $33 \%(15 / 45)$ \\
\hline
\end{tabular}

animals. In cells from control animals the SI was $0.94 \pm 0.01$, which indicates that the spatial properties are quite similar at both frequencies. The average SI for the 3 cells from DR/R animals was $0.69 \pm 0.1$, indicating that in these cells there is a considerable difference in the spatial structure of the RFs at the 2 frequencies tested. The average $\mathrm{SI}$ of the spatial profile of DR/R RFs was significantly different to that of control animals ( $p<$ 0.01). Computation of the SI of the spatiotemporal RF maps for
RGCs from control animals at 5 and $20 \mathrm{~s}$ ISI resulted in a value of $0.69 \pm 0.05$, this value departs from 1 given the aforementioned stronger responses at low stimulation frequency. The SI of the spatiotemporal RF map at ISI of 5 and $20 \mathrm{~s}$ of the 3 RGCs from $\mathrm{DR} / \mathrm{R}$ animals had a value of $0.33 \pm$ 0.07 , indicating a low degree of similarity. The mean SI of spatiotemporal profiles of the 3 cells from DR/R animals differed significantly from control animals $(p<0.01)$.

Further evidence of the strong frequency-dependent habituation in these 3 cells comes from the estimation of the pair pulse index (PPI), which was calculated by dividing the strength of the response (either as spike count or membrane potential fluctuation) to a second stimulus by that of the response to the first stimulus at different interstimulus intervals (ISI). When twin-pulses spaced by intervals ranging from 2.5 to $11 \mathrm{~s}$ were used, PPI values for control cells were always near 1 , whereas at intervals of $2.5 \mathrm{~s}$, cells from DR/R animals had a PPI of $0.24 \pm 0.14$ (mean \pm SE, 3 cells). The PPI of the 3 cells described here from $D R / R$ animals increased as the ISI was increased, approaching 1 at an interval of $11 \mathrm{~s}$ (Fig. $2 F$ ).

\section{Percentage of RGC types in DR/R} animals falls within normal range Following electrophysiological recordings, some RGCs were visually examined using fluorescence microscopy. We could not systematically classify RGCs according to the described types (Sun et al., 2002), but could not observe evidence of gross morphological abnormalities. It has been reported that dark-rearing prevents developmental changes in the proportion of ON, OFF and ON/OFF RGCs. We could unequivocally classify the polarity of ganglion cell responses in 77 of 106 cells recorded from control animals and in 45 of 63 cells recorded from DR/R animals. The percentages of ON cells were very similar in control and DR/R animals $(\sim 50 \%$, Table 1$)$ and were similar to values previously reported for rodent retina from an RGC sample of a similar size (Balkema and Pinto, 1982; Stone and Pinto, 1993; Tian and Copenhagen, 2003). The proportion of OFF cells was larger in control animals, whereas the proportion of ON-OFF cells was somewhat larger in DR/R animals (Table 1). The relatively larger proportion of ON-OFF cells recorded from DR/R animals is, however, not comparable to the much larger percentage of ON-OFF cells found by Tian et al. (2003) in dark-reared animals ( $\sim 80 \%)$, suggesting that after returning $D R / R$ animals to normal light/dark cycles, the developmental changes in the population of ganglion cell types take place as in normal conditions. Thus, the above described functional changes in RF structure seem to occur despite developmental processes at the morphological level apparently resuming after returning the animals to normal light/dark cycles. 

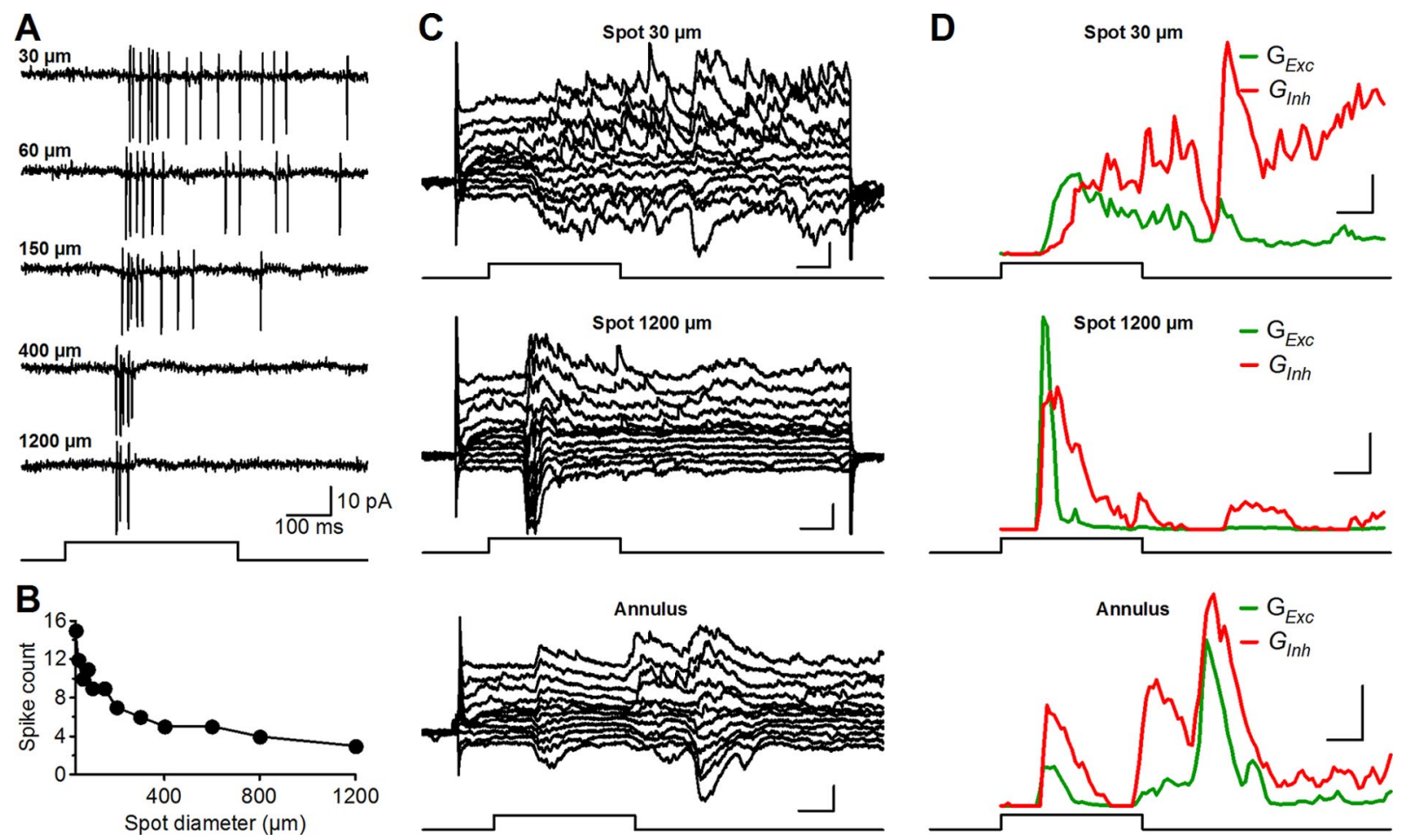

Figure 3. Dissection of light-evoked synaptic currents and conductances underlying RF properties in an RGC from a DR/R animal. $A$, Extracellular recordings of light-evoked responses elicited with spots of different diameter. $\boldsymbol{B}$, Area response function constructed from the complete sequence of spot sizes from spikes recorded extracellularly shown in $\boldsymbol{A}$. $\boldsymbol{C}$, Family of light-evoked currents elicited at holding potentials from -90 to $40 \mathrm{mV}$ every $10 \mathrm{mV}$ with 30 (top traces) and 1200 (middle traces) $\mu \mathrm{m}$ spots and an annulus (300 inner diameter, 1200 outer diameter, bottom traces); Vertical bars: 200 pA, horizontal bars: $100 \mathrm{~ms}$. D, Excitatory and inhibitory conductances computed from the currents shown in C. Vertical bars, $1 \mathrm{nS}$; horizontal bars, $100 \mathrm{~ms}$.

\section{Pattern of excitatory and inhibitory input in control and DR} animals is altered

The output of RGCs depends on the balance of excitatory and inhibitory signals from bipolar and amacrine cells, respectively. Thus, to understand the mechanisms underlying the observed RF changes in RGCs from DR/R animals, we examined the magnitude and spatial distribution of excitatory and inhibitory conductances. Figure $3 \mathrm{~A}$ shows extracellular recordings from an RGC of a $\mathrm{DR} / \mathrm{R}$ animal with similar RF properties to those described above. Figure $3 B$ shows the area response function for this cell, exhibiting a strong response to the smallest spot size and a gradually decreasing magnitude of response to stimulation with larger spots. Figure $3 C$ shows currents recorded after break-in at different holding potentials in response to stimulation with a $30 \mu \mathrm{m}$ spot (top traces), a $1200 \mu \mathrm{m}$ spot (middle traces) and an annulus (inner diameter $300 \mu \mathrm{m}$, outer diameter $1200 \mu \mathrm{m}$; bottom traces). These current-to-voltage relations were used to compute the excitatory and inhibitory synaptic conductances. Figure $3 D$ (top panel) shows that stimulation with a $30 \mu \mathrm{m}$ spot elicited an early excitatory conductance. This excitatory conductance reached its peak and then slowly decayed to $\sim 50 \%$ of the maximum value at the end of the light response. At the peak of the excitatory conductance, the inhibitory conductance started to develop and became stronger than the excitatory conductance. Stimulation with a $1200 \mu \mathrm{m}$ spot resulted in a fast rise in the excitatory conductance concomitant with an increase in inhibitory conductance, with the magnitude of the early excitatory component being initially larger than the inhibitory component but subsequently decaying very rapidly, whereas the inhibitory conductance decayed at a slower rate (middle panel). Stimulation with an annulus produced an almost simultaneous increase in both excitatory and inhibitory conductances, the magnitude of the inhibitory component being larger than that of its excitatory counterpart (Fig. 3D, bottom panel).

We then compared the proportion of excitatory and inhibitory input onto RGCs from control and DR/R animals elicited with stimuli that produce the strongest responses as well as strong inhibition, namely small spots and annuli. The difference between responses of RGCs from control and DR/R animals is illustrated in Figure 4, $A$ and $B$. Recordings from an ON RGC from a control animal show that stimulation with small spots elicited a large excitatory conductance as well as a much smaller inhibitory current, whereas annular stimulation produced a large inhibitory conductance and a smaller excitatory current (Fig. $4 \mathrm{~A}$ ). Stimulation with a $30 \mu \mathrm{m}$ spot in an RGC from a DR/R animal elicited an early excitatory conductance which reached its maximum value and started to decay as a strong inhibitory conductance began to develop, whereas annular stimulation produced both an excitatory and an inhibitory conductance, the latter being stronger. To quantify the relative magnitude of excitatory and inhibitory synaptic conductances, we calculated their integral and estimated the ratio of inhibitory to excitatory input. This analysis was performed only for ON RGCs because we could sample enough of them from $\mathrm{DR} / \mathrm{R}$ animals to allow a comparative analysis with RGCs from control animals. The ratio of inhibition-to-excitation $\left(G_{\text {inh }} / G_{\text {exc }}\right)$ using small spots for control cells was $0.58 \pm 0.16$ ( $n=8$ cells), a value well under 1 , consistent with an overall increase in excitability. In DR/R animals, we used smaller spots for the conductance measurements and the ratio $G_{\text {inh }} / G_{\text {exc }}$ yielded a value of $2.43 \pm 0.7$ ( $n=13$ cells $)$, which was significantly different from the control ratio $(p<0.05)$. Comparison of the $G_{\text {inh }} / G_{\text {exc }}$ evoked with annular stimulation did not show any difference. Figure 4, $D$ and $E$, shows the mean values of the time integral relative to cell capacitance for control and DR/R animals 


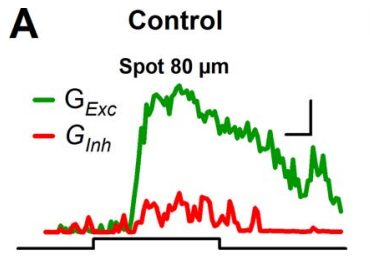

Annulus
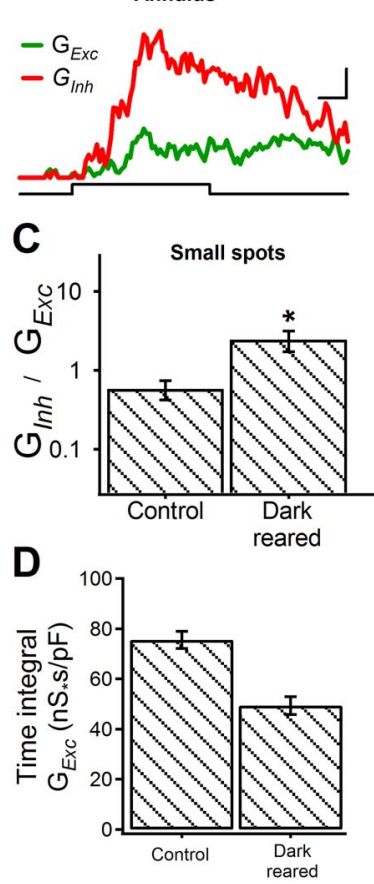

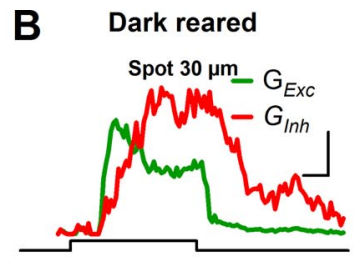

Annulus
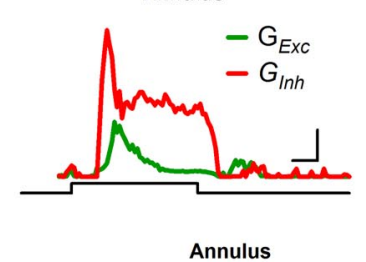

Figure 4. $R G C s$ from $D R / R$ animals display increased inhibitory to excitatory conductance ratio in response to stimulation of RF center. $\boldsymbol{A}$, Examples of excitatory and inhibitory conductances elicited with an $80 \mu \mathrm{m}$ spot (top traces) and an annulus (600/1200 $\mu \mathrm{m}$, inner diameter/ outer diameter; bottom traces) in an RG( from a control animal. Step indicates the onset of light stimulus. Vertical bar, 200 pS; horizontal bar, $100 \mathrm{~ms}$. B, Examples of excitatory and inhibitory conductances elicited with a $30 \mu \mathrm{m}$ spot (top traces) and an annulus $(200 / 1200 \mu \mathrm{m}$, inner diameter/outer diameter; bottom traces). Step indicates the onset of light stimulus. Vertical bars, 200 pS, horizontal bars, $100 \mathrm{~ms}$ for spot response and annulus responses, respectively. C, Ratio of time integral of inhibitory-to-excitatory conductance elicited with optimal spot diameter and annuli measured in RGCs from control and DR/R animals. The ratio was significantly larger ( ${ }^{*} p<0.05$ ) in response to stimulation with small spots for DR/Ranimals, whereas no difference was observed for annular stimulation. $\boldsymbol{D}$, Mean magnitude of the time integral of excitatory conductance from 8 RGCs from control animals is larger than that measured from 13 RGCs from DR/R animals but not significantly different. $E$, Mean value of the time integral of inhibitory conductance for 8 RGCs from control animals is smaller than that recorded from 13 RGCs from DR/R animals, although this difference was not significant.

for excitatory and inhibitory conductance, respectively, in response to stimulation with a small spot. Although a trend toward smaller excitatory and larger inhibitory conductance is observed in cells from DR/R animals, no significant difference was found $(t$ test; 8 control and $13 \mathrm{DR} / \mathrm{R}$ cells). These results provide critical information about the net synaptic input by looking at the balance between excitation and inhibition in comparison to all other studies in which only either excitatory or inhibitory inputs were investigated.

To investigate whether or not excitatory inputs were modified by visual deprivation we quantified the spatial profile of the excitatory input of the light-evoked charge transfer. Spatial tuning curves were fit using a DOG model, from which the strength of the center and surround as well as their radii was estimated. Excitatory inputs from 7 ON RGCs of control and 9 ON RGCs of
DR/R animals were spatially tuned. Difference of Gaussians fits for control and DR cells revealed that excitatory inputs are summated up to spot sizes between 40 and $100 \mu \mathrm{m}$ for both control and DR/R and then the curves roll off, denoting presynaptic surround inhibition. The parameters obtained from the DOG fits showed that the average for center radius was $72 \pm 13 \mu \mathrm{m}$ in control cells $(n=7)$ and $88 \pm 19 \mu \mathrm{m}$ in DR/R cells $(n=9)$, values which are not significantly different. The surround radius was $423 \pm 108 \mu \mathrm{m}$ in control cells $(n=7)$ and $369 \pm 67 \mu \mathrm{m}$ in DR/R cells $(n=9)$, not significantly different. We estimated the ratio of the integrated volume of the surround to the integrated volume of the center for the excitatory input, which provides a faithful approximation of the impact of surround inhibition due to stimulation with large spots. The ratio was $0.84 \pm 0.076$ for control and $0.83 \pm 0.063$ for DR/R cells. These values are not significantly different and they fall in the ranges reported for cat (0.73 and 0.8) (Rodieck and Stone, 1965; Linsenmeier et al., 1982, respectively) and primate ganglion cells (0.55) (Croner and Kaplan, 1995). These results indicate that the excitatory inputs are spatially tuned and their spatial profile is not affected by dark-rearing.

In other visual areas, it has been shown that excitatory and inhibitory inputs change not only their relative strengths during development but also their spatial distribution within the RF (Hensch and Fagiolini, 2005; Tao and Poo, 2005). To map the RF structure of the excitatory and inhibitory inputs onto RGCs, we stimulated a small area of the RF comprising the center and the immediate surround with small spots, while voltage-clamping the cells at $-55 \mathrm{mV}\left(\sim E_{\mathrm{GABA} / \mathrm{Gly}}\right.$, to isolate direct excitatory input) and at $0 \mathrm{mV}$ ( $\sim E_{\mathrm{Glu}}$, to isolate direct inhibitory input). The center of the stimulus was generally aligned with the strongest spike response recorded during extracellular recordings. Figure $5 A$ shows a color-coded RF map for the excitatory inputs quantified as the time integral of the light-evoked synaptic currents for an RGC from a control and a DR/R animal. The structure of excitatory RF maps looked very similar in RGCs from control and $\mathrm{DR} / \mathrm{R}$ animals showing the strongest response at the center of the RF. RF maps of inhibitory inputs for the same RGCs are shown in Figure $5 B$. The strongest inhibitory response for the control RGC is observed in the center of the stimulus grid, matching the spatial profile of the excitatory input. The strongest inhibitory response in the RGC from the DR/R animal was located at the periphery of the grid and does not spatially coincide with the peak excitation at the center. Moreover, the pixels producing the strongest inhibitory responses appeared scattered in the stimulus matrix. Excitatory and inhibitory inputs were measured from eRF and iRF maps, respectively, for different cells and pooled to graph them with respect to the distance to the center of the grid. To avoid clutter, only the maximum response and the second largest response (if it reached at least $80 \%$ of the maximum value) were plotted. Figure $5 \mathrm{Ca}$ shows pooled data for 7 RGCs (4 ON, 2 OFF and $1 \mathrm{ON}-\mathrm{OFF}$ ) from control animals, in which all maximum excitatory inputs overlap in the center and a second response for a cell appears in a nearby location. Pooled data for the excitatory inputs from 18 RGCs (9 ON, 5 OFF and 4 ON-OFF) from DR/R animals are shown in Figure $5 \mathrm{Cb}$. The maximum strength for excitatory input is localized to the center in all RGC, with only one cell showing the peak response at the closest distance tested from the center. Figure $5 D$ shows the spatial location of the strongest inhibitory inputs for the same set of RGCs from control and DR/R animals. Inhibitory inputs in control cells (Fig. 5Da) are all restricted to the region around the center and a larger proportion of cells displayed a secondary response. Pooled data for the inhibitory inputs of the 18 RGCs from DR/R animals are shown in 
A

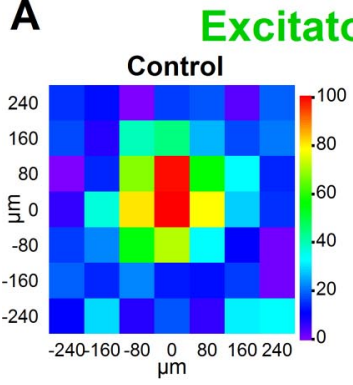

C a

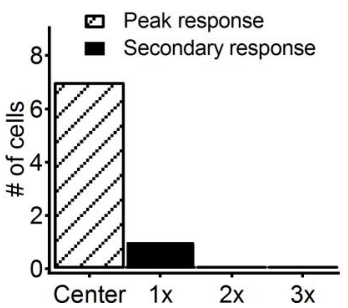

Excitatory input Dark reared/recovery

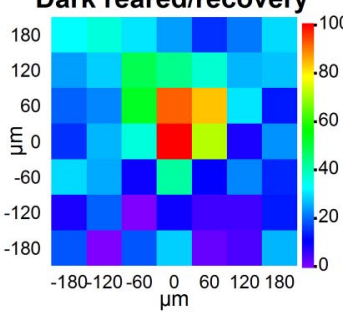

$\mathrm{b}$

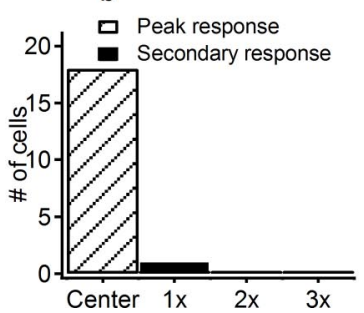

B

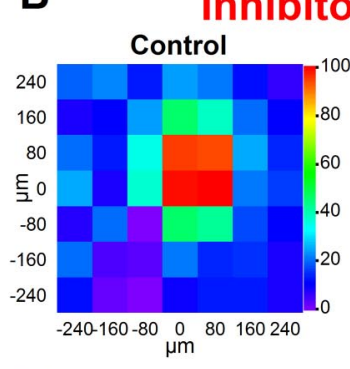

D a

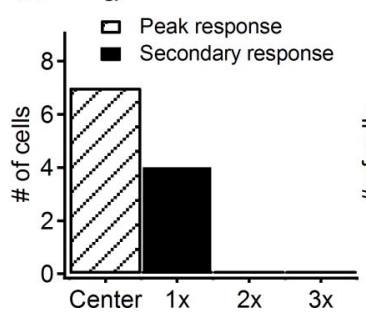

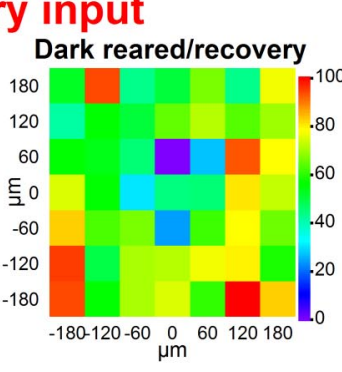

b

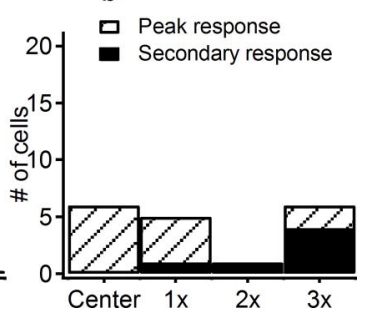

Figure 5. Excitatory and inhibitory RF maps are spatially mismatched in DR/R animals. $A$, Representative excitatory RF maps of an RGC from a control and a DR/R animal using small spots ( 30 - 80 $\mu \mathrm{m}$ ). Integral of light-evoked currents (charge) are displayed with respect to the position of the spot in 49 different locations in the central area of the RF in a pseudocolor scale normalized to the maximal response. eRFs for the control cell were elicited with an $80 \mu \mathrm{m}$ spot and for the RGCs of DR/R animal with a $60 \mu \mathrm{m}$ spot while voltage-clamping RGCs at $-55 \mathrm{mV}$. $\boldsymbol{B}$, Representative inhibitory RF maps for the same RGCs shown in $A$ using same stimulus parameters. Charge is displayed as a function of spot position for light-evoked currents elicited while voltage-clamping RGCs at $0 \mathrm{mV}$, pseudocolor scale normalized to maximum response. C, Pooled data for eRFs, plotting the spatial location of the maximum response, and second largest response when it exceeded a threshold of $80 \%$ of the peak response, obtained from 7 RGCs from control animals $(\boldsymbol{a})$ and $18 \mathrm{RGCs}$ from DR/R animals $(\boldsymbol{b})$. To facilitate grouping and comparison among different cells, radii are symbolized by $x$, where $x$ (ranging between 30 and $80 \mu \mathrm{m}$ ) was optimized for individual cells. Note that in most cells the locations of maximum excitatory inputs are localized to the center of the grid. $\boldsymbol{D}$, Pooled data obtained for iRFs, plotting the spatial location of the maximum response, and secondary response, for 7 and $18 \mathrm{RGCs}$ from control (a) and DR/R (b) animals, respectively. The locations of peak inhibitory inputs in control RGCs was always in the center and in register with the maximum excitatory input, whereas locations of maximum inhibitory inputs in DR/R are scattered across different positions of the graph. Radii are symbolized by $x$, where $x$ ranged between 30 and $80 \mu \mathrm{m}$.

Figure $5 D b$. The maximum inhibitory inputs appear scattered over most of the locations tested, with a large number of them far away from the center, indicating a mismatch of the areas in the RF that generate maximal excitatory and inhibitory input. Secondary responses were also scattered and frequently observed in the periphery of the grid. Overall, eRF and iRF maps showed a lack of registration of peak responses in 12 of the 18 RGCs from DR/R animals tested, including all cell types (6 ON, 4 OFF and $2 \mathrm{ON}$ OFF RGC).

To quantify this effect of visual deprivation, we estimated a measure of the distance between pixels that produce the strongest excitatory and inhibitory currents within the stimulated area of the RF (see Materials and Methods). The mean value for the separation of excitatory and inhibitory synaptic inputs in RGCs from control animals was $65 \pm 12 \mu \mathrm{m}$, whereas in DR/R animals it was $163 \pm 29 \mu \mathrm{m}$, a significant difference (Fig. $6 A, p<0.05$ ) that indicates a bigger scatter of the inhibitory with respect to the excitatory inputs across the RF. These values, representing a mismatch of inputs, were obtained when using a similar number of pixels to those which evoked the strongest excitatory and inhibitory inputs for cells from both control and DR/R animals (Fig. $6 B, C)$, thus the higher degree of separation between excitatory and inhibitory inputs observed in cells from DR/R animals actually reflects scattered inputs and not differences in the numbers of pixels used for the calculation.

\section{Discussion}

Our study shows that visual deprivation from birth to P62-P119 causes profound long-term changes in the physiological properties of rat retinal ganglion cells. Overall, in DR/R animals, excitatory drive onto RGCs was reduced, direct inhibitory input was increased and the spatial organization of their receptive fields was
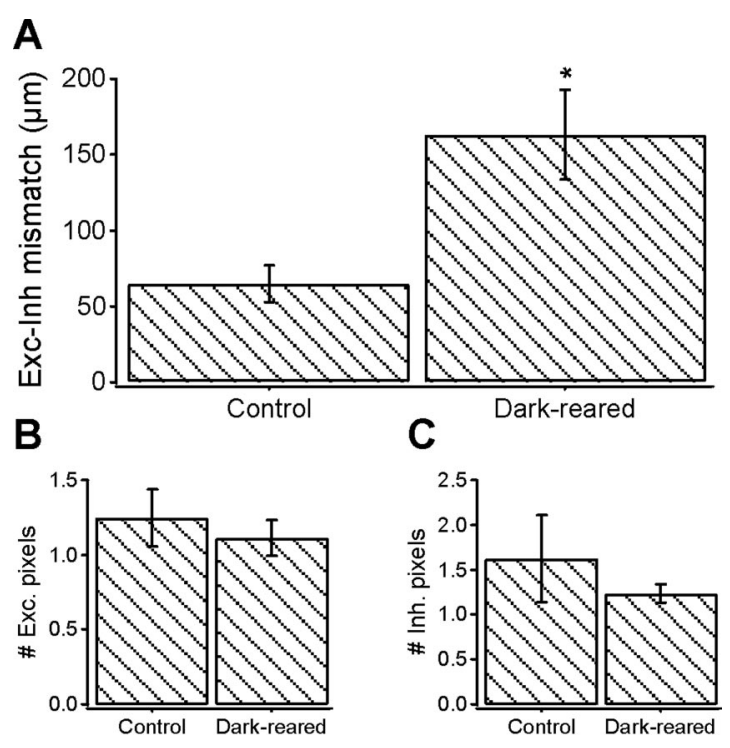

Figure 6. Excitatory and inhibitory inputs in DR/R animals display a higher degree of spatial mismatch. $A$, Mean distance between all unique excitatory and inhibitory pairs for an average of 7 and 10 cells from control and DR/R animals, respectively. Only locations in which small spots elicited a response above a threshold of $80 \%$ of the maximal response were considered for this measurement. The mean distance between excitatory and inhibitory locations was significantly larger in DR/Ranimals (mean $\pm \mathrm{SE},{ }^{*} p<0.05$ ). $\boldsymbol{B}$, Average number of excitatory pixels eliciting a response above threshold used for the computation of the spatial mismatch of excitatory and inhibitory inputs. No significant difference was observed between control and DR/R animals (mean $\pm \mathrm{SE}$ ). C, Average number of inhibitory pixels provoking a response above threshold used for the computation of the spatial mismatch of excitatory and inhibitory inputs. No significant difference was observed between control and DR/R animals (mean $\pm \mathrm{SE}$ ). 
disrupted. Recovery from dark rearing from 2 to 8 months did not to restore normal responses in RGCs.

\section{Long-lasting effects of light deprivation on retinal and other visual neurons}

The possibility that visual deprivation might permanently alter retinal circuitry was first suggested by evidence that APB treatment during the first month of postnatal life of the cat induced permanent modifications in RGC function, including an increase in the proportion of RGCs with ON-OFF discharges and loss of surround inhibition (Bisti et al., 1998) and an increase in the percentage of multistratifying RGCs (Deplano et al., 2004). A recent report by Giovanelli et al. (2008) showed that in LongEvans rats, early prolonged visual deprivation reduced the spontaneous synaptic activity recorded of RGCs. Here we describe pronounced changes in RGC excitability and RF organization, following dark-rearing for periods spanning the critical period for ocular dominance plasticity in rats (between P23 and P50; Fagiolini et al., 1994). Our results thus highlight the importance of early visual experience for normal retinal development.

Recovery of behaviorally measured visual acuity after visual deprivation is only partial, whether in rodents (Prusky et al., 2000; Prusky and Douglas, 2003) or cats (Timney et al., 1978), even when long periods are allowed for recovery. Correspondingly, cortical visual properties, such as orientation, direction selectivity and binocularity of neurons remain impaired by dark rearing even after prolonged recovery in cat (Cynader et al., 1976) and ferret (Liao et al., 2004). Interestingly, changes in the RF size of superior colliculus neurons induced by dark rearing also appear to be permanent, emphasizing that early visual experience is critical for the appropriate wiring of the neuronal networks in multiple visual regions (Carrasco et al., 2005). We suggest that these long-lasting changes in the RF properties of RGCs contribute to altered neuronal properties in higher visual areas.

\section{Light deprivation strongly modified RGC receptive field properties}

Early visual deprivation produced significant changes in the RF profile of RGCs, consisting of a reduction in RF center and surround size with a concomitant increase in the surround strength. In addition, the average amplitude of the strongest responses from DR/R cells was considerably smaller than those of control cells. The effects of dark-rearing on the receptive field properties in turtle retina were shown not to be reversible (Merwine et al., 1998, cited by Lee et al., 2006), similar to our findings although dark-rearing in the turtle retina resulted in an expansion of RF sizes (Sernagor and Grzywacz, 1996) rather than a reduction. The reduction we observed in RF size of RGCs is in contrast to the effect of dark rearing on RF size in other visual regions; visual deprivation has been shown to induce expansion of RFs in the rat visual cortex (Fagiolini et al., 1994) and in the hamster superior colliculus (Carrasco et al., 2005). The two inhibitory mechanisms observed at high and low-frequency stimulation (Fig. 2) suggest that the function of narrow and wide field amacrine cells in DR/R animals is different from in normally reared adult animals. Consistent with this idea, visual deprivation has been shown to modify both the physiological responses (Osswald et al., 2007) and the spatial arrangement of amacrine cells (Zhang et al., 2005).

The use of twin-stimulus protocols confirmed the frequency dependence of the strong inhibition, known as habituation, observed in this group of cells. In the adult retina, responses from RGCs rarely habituate (our data; Barlow et al., 1964; Hochstein and Shapley, 1976), whereas the weak responses present at early developmental stages fatigue easily in the retina (Masland, 1977; Tootle, 1993) and dLGN (Daniels et al., 1978). In rat visual cortex, at P17 82\% of neurons habituate for interstimulus intervals shorter than $15 \mathrm{~s}$, a similar proportion to that observed in dark reared rats (Fagiolini et al., 1994). Our experiments show that habituation persists in some RGCs of visually deprived animals even after a long period of recovery in normal light/dark cycles.

In our study, the percentage of ON-OFF RGCs in DR/R animals was similar to that in the normal adult retina and to that observed after reversal of dark rearing effects in the mouse retina (Tian and Copenhagen, 2003). A high proportion of ON-OFF responses and multistratifying RGCs is characteristic of early developmental stages, the proportion decreasing during development. The high neonatal percentage is preserved, however, by both visual deprivation and pharmacological manipulation (treatment with APB). Similarly, at early developmental stages a larger proportion of ON-OFF cells is present in the ferret LGN and dark-rearing prevents both the selective loss of ON-OFF responses (Akerman et al., 2002). The gross morphological characteristics of the RGCs we recorded from in DR/R animals seemed to be similar to those from control animals. This suggests that after dark rearing for a time that encompasses the critical period, there is still substantial plasticity that allows for developmental pruning after returning to normal light/dark cycles, as previously shown by Tian and Copenhagen (2003). The observed changes in response strength, habituation, spatial profile and spatial organization of the RF and relative strength of inhibitory and excitatory inputs, however, indicate that maturational processes involved in the refinement of synaptic connections are disrupted and altered by visual deprivation.

It is unlikely that RGCs recorded from DR/R animals displaying abnormal RF properties and/or enhanced inhibitory activity correspond to particular cell types which were not sampled in control animals, since we used the same selection criteria based on soma size and on the presence of large inward voltage gated sodium currents for DR/R and control animals. In addition, we observed homogeneity in the type of responses from a similar number of cells in both DR/R and control animals and comparison of many of the parameters quantified in these two groups revealed statistical significance. Moreover, we never recorded responses with characteristics of $D R / R$ responses from control animals.

\section{An imbalance in the ratio of inhibitory-excitatory input onto RGCs of DR/R cells underlies their abnormal responsiveness} Our study looked at the balance between excitation and inhibition providing critical information about the net synaptic inputs onto RGC. The imbalance in the strength of excitatory and inhibitory circuits is likely to be the consequence of complete early visual deprivation. It has been shown that GABAergic input onto pyramidal cells in the rat visual cortex increases threefold through the critical period, and this increase is prevented by dark rearing from birth (Morales et al., 2002). Moreover, genetic manipulation of the levels of GABAergic inhibition in visual cortex using GAD65 KO mice, abolishes cortical ocular dominance plasticity, which can be restored by enhancing inhibitory activity pharmacologically (Hensch et al., 1998). More recently, it was also shown that visual deprivation reduces GABAA receptors in a specific cellular compartment (soma-proximal dendrite) but not in others (axon initial segment) in mouse visual cortex and that receptor density is finely regulated during development to enable plasticity (Katagiri et al., 2007). Lee et al. (2006) showed that the levels of GABA and GAD65 (one of its synthesizing enzymes) 
were reduced in the inner nuclear and ganglion cell layers of P30 dark-reared animals compared with control retinas. This reduction was shown to be reversed by returning the animals to a normal light/dark cycle for $15 \mathrm{~d}$. Interestingly, the same study also showed that despite the observed recovery of both GABA and GAD65 levels, dark-rearing produced a significant reduction $(\sim 19 \mu \mathrm{m})$ in the thickness of the inner nuclear layer which is not reversed by light exposure, demonstrating clearly that changes in the structure of the inner plexiform layer are not fully reversible. In agreement with our observations of long-term changes in RF properties due to early visual deprivation, the effects of darkrearing on the receptive field properties in turtle retina are not reversible (Merwine et al., 1998, cited by Lee et al., 2006). Interestingly, dark rearing also enhances the strength of the inhibitory surround in directionally selective RGCs in the rabbit (Chan and Chiao, 2008) even when it does not disrupt the wiring of the circuit that generates direction selectivity (Chan and Chiao, 2008; Elstrott et al., 2008).

In addition, we found that in most RGCs from DR/R animals the spatial location of the peak of the excitatory and inhibitory components of the RF are spatially mismatched, as opposed to control cells and to the classical RF model of RGCs (Rodieck, 1965; Enroth-Cugell and Robson, 1966) and that on average the degree of separation between the position of the peak of excitation and inhibition in DR/R animals is larger than in controls. Moreover, the lack of registration observed in eRF and iRF maps may lead to an underestimation of the ratio of inhibitory to excitatory conductance measured in response to small spots. The similarities in the values obtained for the center and surround radii and for the ratio of the integrated volume of the surround to center indicate that excitatory inputs onto RGCs are not affected by dark-rearing/recovery and point out to the direct inhibitory inputs and inner plexiform layer function as the source of the functional changes observed in RF properties.

It has been reported that RFs in the Xenopus optic tectum undergo developmental changes that involve a reduction in the strength of inhibitory inputs as well as the spatial matching of the excitatory and inhibitory components of the RF; and blockade or enhancement of GABAergic activity prevents size tuning and topographic mapping of excitatory and inhibitory inputs (Tao and Poo, 2005). Whether similar mechanisms may operate in the retina is unknown. Of relevance to our study, it has been established that the RF shape and size of RGCs changes during development as the proportion of RGCs with concentric RFs in both the turtle and rabbit retina increases from only $6-25 \%$ early in development to $\sim 60 \%$ in the adult retina (Masland, 1977; Sernagor and Grzywacz, 1995). Although it is unknown whether or not excitatory and inhibitory inputs undergo refinement and alignment during development and how they relate to RF size, it is likely that they experience similar modifications to those reported for other visual areas.

We conclude that complete visual deprivation from birth throughout the critical period of sensitivity permanently modifies the functional properties of RGCs. These results show for the first time that dark rearing causes an imbalance in the strength of inhibitory and excitatory inputs in the retina as well as their spatial mismatch. The changes observed in response strength and receptive field spatio-temporal properties suggest that alterations at an early stage of visual processing can contribute to the changes in RF properties and loss of plasticity reported in higher visual areas after early long-term visual deprivation.

\section{References}

Akerman CJ, Smyth D, Thompson ID (2002) Visual experience before eyeopening and the development of the retinogeniculate pathway. Neuron 36:869-879.

Balkema GW Jr, Pinto LH (1982) Electrophysiology of retinal ganglion cells in the mouse: a study of a normally pigmented mouse and a congenic hypopigmentation mutant, pearl. J Neurophysiol 48:968-980.

Barlow HB, Hill RM, Levick WR (1964) Retinal ganglion cells responding selectively to direction and speed of image motion in the rabbit. J Physiol 173:377-407.

Baro JA, Lehmkuhle S, Kratz KE (1990) Electroretinograms and visual evoked potentials in long-term monocularly deprived cats. Invest Ophthalmol Vis Sci 31:1405-1409.

Bisti S, Gargini C, Chalupa LM (1998) Blockade of glutamate-mediated activity in the developing retina perturbs the functional segregation of $\mathrm{ON}$ and OFF pathways. J Neurosci 18:5019-5025.

Bodnarenko SR, Chalupa LM (1993) Stratification of ON and OFF ganglion cell dendrites depends on glutamate-mediated afferent activity in the developing retina. Nature 364:144-146.

Bodnarenko SR, Jeyarasasingam G, Chalupa LM (1995) Development and regulation of dendritic stratification in retinal ganglion cells by glutamate-mediated afferent activity. J Neurosci 15:7037-7045.

Bodnarenko SR, Yeung G, Thomas L, McCarthy M (1999) The development of retinal ganglion cell dendritic stratification in ferrets. Neuroreport 10:2955-2959.

Borg-Graham LJ (2001) The computation of directional selectivity in the retina occurs presynaptic to the ganglion cell. Nat Neurosci 4:176-183.

Carrasco MM, Razak KA, Pallas SL (2005) Visual experience is necessary for maintenance but not development of receptive fields in superior colliculus. J Neurophysiol 94:1962-1970.

Chan YC, Chiao CC (2008) Effect of visual experience on the maturation of ON-OFF direction selective ganglion cells in the rabbit retina. Vision Res 48:2466-2475.

Coombs J, Van Der List D, Chalupa LM (2007) Morphological properties of mouse retinal ganglion cells during postnatal development. J Comp Neurol 503:803-814.

Croner LJ, Kaplan E (1995) Receptive fields of P and M ganglion cells across the primate retina. Vision Res 35:7-24.

Cynader M, Berman N, Hein A (1976) Recovery of function in cat visual cortex following prolonged deprivation. Exp Brain Res 25:139-156.

Daniels JD, Pettigrew JD, Norman JL (1978) Development of single-neuron responses in kitten's lateral geniculate nucleus. J Neurophysiol 41:1373-1393.

DeAngelis GC, Ghose GM, Ohzawa I, Freeman RD (1999) Functional micro-organization of primary visual cortex: receptive field analysis of nearby neurons. J Neurosci 19:4046-4064.

Demb JB, Haarsma L, Freed MA, Sterling P (1999) Functional circuitry of the retinal ganglion cell's nonlinear receptive field. J Neurosci 19:9756-9767.

Deplano S, Gargini C, Maccarone R, Chalupa LM, Bisti S (2004) Long-term treatment of the developing retina with the metabotropic glutamate agonist APB induces long-term changes in the stratification of retinal ganglion cell dendrites. Dev Neurosci 26:396-405.

Diao L, Sun W, Deng Q, He S (2004) Development of the mouse retina: emerging morphological diversity of the ganglion cells. J Neurobiol 61:236-249.

Elstrott J, Anishchenko A, Greschner M, Sher A, Litke AM, Chichilnisky EJ, Feller MB (2008) Direction selectivity in the retina is established independent of visual experience and cholinergic retinal waves. Neuron 58:499-506.

Enroth-Cugell C, Robson JG (1966) The contrast sensitivity of retinal ganglion cells of the cat. J Physiol 187:517-552.

Enroth-Cugell C, Robson JG (1984) Functional characteristics and diversity of cat retinal ganglion cells. Basic characteristics and quantitative description. Invest Ophthalmol Vis Sci 25:250-267.

Fagiolini M, Pizzorusso T, Berardi N, Domenici L, Maffei L (1994) Functional postnatal development of the rat primary visual cortex and the role of visual experience: dark rearing and monocular deprivation. Vision Res 34:709-720.

Fischer KF, Lukasiewicz PD, Wong RO (1998) Age-dependent and cell class-specific modulation of retinal ganglion cell bursting activity by GABA. J Neurosci 18:3767-3778. 
Giovannelli A, Di Marco S, Maccarone R, Bisti S (2008) Long-term dark rearing induces permanent reorganization in retinal circuitry. Biochem Biophys Res Commun 365:349-354.

Grubb MS, Thompson ID (2004) The influence of early experience on the development of sensory systems. Curr Opin Neurobiol 14:503-512.

Hensch TK, Fagiolini M (2005) Excitatory-inhibitory balance and critical period plasticity in developing visual cortex. Prog Brain Res 147:115-124.

Hensch TK, Fagiolini M, Mataga N, Stryker MP, Baekkeskov S, Kash SF (1998) Local GABA circuit control of experience-dependent plasticity in developing visual cortex. Science 282:1504-1508.

Hochstein S, Shapley RM (1976) Quantitative analysis of retinal ganglion cell classifications. J Physiol 262:237-264.

Huberman AD, Feller MB, Chapman B (2008) Mechanisms underlying development of visual maps and receptive fields. Annu Rev Neurosci 31:479-509.

Katagiri H, Fagiolini M, Hensch TK (2007) Optimization of somatic inhibition at critical period onset in mouse visual cortex. Neuron 53:805-812.

Kuffler SW (1953) Discharge patterns and functional organization of mammalian retina. J Neurophysiol 16:37-68.

Landi S, Cenni MC, Maffei L, Berardi N (2007) Environmental enrichment effects on development of retinal ganglion cell dendritic stratification require retinal BDNF. PLoS One 2:e346.

Lee EJ, Gibo TL, Grzywacz NM (2006) Dark-rearing-induced reduction of GABA and GAD and prevention of the effect by BDNF in the mouse retina. Eur J Neurosci 24:2118-2134.

Leitch E, Coaker J, Young C, Mehta V, Sernagor E (2005) GABA type-A activity controls its own developmental polarity switch in the maturing retina. J Neurosci 25:4801-4805.

Liao DS, Krahe TE, Prusky GT, Medina AE, Ramoa AS (2004) Recovery of cortical binocularity and orientation selectivity after the critical period for ocular dominance plasticity. J Neurophysiol 92:2113-2121.

Linsenmeier RA, Frishman LJ, Jakiela HG, Enroth-Cugell C (1982) Receptive field properties of $\mathrm{X}$ and $\mathrm{Y}$ cells in the cat retina derived from contrast sensitivity measurements. Vision Res 22:1173-1183.

Liu X, Grishanin RN, Tolwani RJ, Rentería RC, Xu B, Reichardt LF, Copenhagen DR (2007a) Brain-derived neurotrophic factor and TrkB modulate visual experience-dependent refinement of neuronal pathways in retina. J Neurosci 27:7256-7267.

Liu Y, Zhang LI, Tao HW (2007b) Heterosynaptic scaling of developing GABAergic synapses: dependence on glutamatergic input and developmental stage. J Neurosci 27:5301-5312.

Masland RH (1977) Maturation of function in the developing rabbit retina. J Comp Neurol 175:275-286.

Maslim J, Stone J (1988) Time course of stratification of the dendritic fields of ganglion cells in the retina of the cat. Dev Brain Res 44:87-93.

Mehta V, Sernagor E (2006a) Early neural activity and dendritic growth in turtle retinal ganglion cells. Eur J Neurosci 24:773-786.

Mehta V, Sernagor E (2006b) Receptive field structure-function correlates in developing turtle retinal ganglion cells. Eur J Neurosci 24:787-794.

Merwine DK, Grzywacz NM, Amthor FR (1998) Persistent effects of dark rearing on the development of turtle retinal ganglion cells. Soc Neurosci Abstr 24:600.10.

Mitchell DE (1988) The extent of visual recovery from early monocular or binocular visual deprivation in kittens. J Physiol 395:639-660.

Morales B, Choi SY, Kirkwood A (2002) Dark rearing alters the development of GABAergic transmission in visual cortex. J Neurosci 22:80848090 .
Mumm JS, Godinho L, Morgan JL, Oakley DM, Schroeter EH, Wong RO (2005) Laminar circuit formation in the vertebrate retina. Prog Brain Res 147:155-169.

Osswald IK, Galan A, Bowie D (2007) Light triggers expression of philanthotoxin-insensitive $\mathrm{Ca} 2+$-permeable AMPA receptors in the developing rat retina. J Physiol 582:95-111.

Prusky GT, Douglas RM (2003) Developmental plasticity of mouse visual acuity. Eur J Neurosci 17:167-173.

Prusky GT, West PW, Douglas RM (2000) Experience-dependent plasticity of visual acuity in rats. Eur J Neurosci 12:3781-3786.

Rodieck RW (1965) Quantitative analysis of cat retinal ganglion cell response to visual stimuli. Vision Res 5:583-601.

Rodieck RW, Stone J (1965) Analysis of receptive fields of cat retinal ganglion cells. J Neurophysiol 28:832-849.

Sernagor E, Grzywacz NM (1995) Emergence of complex receptive field properties of ganglion cells in the developing turtle retina. J Neurophysiol 73:1355-1364.

Sernagor E, Grzywacz NM (1996) Influence of spontaneous activity and visual experience on developing retinal receptive fields. Curr Biol 6:1503-1508.

Sernagor E, Young C, Eglen SJ (2003) Developmental modulation of retinal wave dynamics: shedding light on the GABA saga. J Neurosci 23:76217629.

Stone C, Pinto LH (1993) Response properties of ganglion cells in the isolated mouse retina. Vis Neurosci 10:31-39.

Sun W, Li N, He S (2002) Large-scale morophological survey of rat retinal ganglion cells. Vis Neurosci 19:483-493.

Tao HW, Poo MM (2005) Activity-dependent matching of excitatory and inhibitory inputs during refinement of visual receptive fields. Neuron 45:829-836.

Taylor WR, Vaney DI (2002) Diverse synaptic mechanisms generate direction selectivity in the rabbit retina. J Neurosci 22:7712-7720.

Tian N, Copenhagen DR (2001) Visual deprivation alters development of synaptic function in inner retina after eye opening. Neuron 32:439-449.

Tian N, Copenhagen DR (2003) Visual stimulation is required for refinement of ON and OFF pathways in postnatal retina. Neuron 39:85-96.

Timney B, Mitchell DE, Giffin F (1978) The development of vision in cats after extended periods of dark-rearing. Exp Brain Res 31:547-560.

Tootle JS (1993) Early postnatal development of visual function in ganglion cells of the cat retina. J Neurophysiol 69:1645-1660.

Wang CT, Blankenship AG, Anishchenko A, Elstrott J, Fikhman M, Nakanishi S, Feller MB (2007) GABAA receptor-mediated signaling alters the structure of spontaneous activity in the developing retina. J Neurosci 27:9130-9140.

Wang GY, Liets LC, Chalupa LM (2001) Unique functional properties of on and off pathways in the developing mammalian retina. J Neurosci 21:4310-4317.

Wiesel TN, Hubel DH (1963) Effects of visual deprivation on morphology and physiology of cells in the cats lateral geniculate body. J Neurophysiol 26:978-993.

Zhang J, Yang Z, Wu SM (2005) Development of cholinergic amacrine cells is visual activity-dependent in the postnatal mouse retina. J Comp Neurol 484:331-343.

Zhang LL, Pathak HR, Coulter DA, Freed MA, Vardi N (2006) Shift of intracellular chloride concentration in ganglion and amacrine cells of developing mouse retina. J Neurophysiol 95:2404-2416. 